\title{
Epidemiological survey of maintenance workers in London Transport Executive bus garages and Chiswick Works
}

\author{
L RUSHTON, M R ALDERSON, AND C R NAGARAJAH \\ From the Institute of Cancer Research, Sutton, Surrey SM2 SPX, UK
}

ABSTRACT A mortality study of maintenance men employed for at least one year between 1
January 1967 and 31 December 1975 at 71 London Transport bus garages and Chiswick Works
has been carried out. Over $97 \%$ of the population were successfully traced to determine their
vital status at 31 December 1975 . The mortality observed in the study population was compared
with that which would be expected from the mortality rates for the all male population of
England and Wales. The mortality of the study population from all causes was much lower than
expected on this basis, as was the mortality from cerebrovascular disease, ischaemic heart disease,
and bronchitis. Mortality from all neoplasms was slightly less than expected overall and especially
in the younger age groups. The observed deaths from cancer of the lung were approximately the
same as those expected on the basis of national rates. Nevertheless, a deficit of observed deaths
from lung cancer was obtained after adjusting for the higher mortality from this disease in
Greater London. Raised mortality was found in subgroups of the population for several malig-
nant disease groups but these were almost all based on small numbers of deaths, making it
difficult to exclude chance effects. Both the number of men and deaths in the study were limited
and the follow up time was also short. Considerable extension of the study to include more men
and increase the follow up time would be required for any definite mortality patterns to emerge.

The aim of this study was to examine the patterns of mortality by cause for maintenance workers at London Transport bus garages and Chiswick Works. This is the fourth part of a wider study of workers in the oil industry which has been carried out by the same research team..$^{1-3}$ As users of several of the products of the oil industry, it was suggested that the London Transport workers would provide a useful comparison group for the refinery and distribution centre workers.

\section{Previous studies of London Transport workers}

There has been a series of papers spanning several years reporting on work being carried out to investigate coronary heart disease in London Transport employees, particularly in bus drivers and conductors. ${ }^{4-11}$ In a study of workers during 1949 and 1950 it was first shown that coronary heart disease was less frequent in conductors than in bus drivers. ${ }^{4}$

Received 2 June 1982

Accepted 25 August 1982
Further studies included a follow up study of those men who survived three months, ${ }^{5}$ examination of sickness absence before the onset of coronary heart disease ${ }^{8}$ measurement of the physique of busmen, ${ }^{69}$ and the association of coronary artery disease with "stress." " A five year follow up of a group of busmen with no evidence of ischaemic heart disease when first examined showed an association of ischaemic heart disease with high levels of either systolic blood pressure or plasma cholesterol. ${ }^{7}$

There has been concern about the effect of diesel exhaust on health, particularly on the incidence of lung cancer. Air pollution was measured in two London Transport diesel bus garages with only natural draft ventilation. ${ }^{12}$ Concentrations of smoke were found to be higher inside the garages than outside and high concentrations of smoke inside the garages correlated with periods of greatest bus movement; only small differences in the concentrations of hydrocarbon were found.

The incidence of lung cancer among several categories of London Transport employees during 1950-4 was examined and showed that the inci- 
dence among the diesel bus garage workers was no higher than that expected among the general population. ${ }^{8}$ It was pointed out, however, that since diesel buses had only been gradually introduced since the 1930s there may not have been adequate duration of exposure or latency time to observe an increase in the number of cases of lung cancer. ${ }^{13}$

Some preliminary results have been reported from a study of all cases of lung cancer since 1950 arising during service in five categories of London Transport workers, including engineers in bus garages and the central works. ${ }^{14}$ In each category the observed numbers of lung cancers were below those expected on the basis of Greater London death rates. The highest mortality ratio was among bus garage workers although this did not differ significantly from the Underground motormen and guards who do not have any special diesel fume exposure. It was also pointed out that the smoking habits of the men were not known. Air pollution sampling was again carried out in the same two garages as before. ${ }^{12}$ The background concentration of benzo(a)pyrene in the outside air was found to be very much lower than in 1957 and the concentrations within the garages were also correspondingly reduced.

\section{Method}

The present study included all maintenance men with a length of service of at least one continuous year between 1 January 1967 and 31 December 1975 at 71 London Transport bus garages and the engineering works at Chiswick. The bus garages are collectively referred to as rolling stock by London Transport and this term has also been used in this paper.

For all men surname, initials, date of birth, date of joining, last or present job, and location of work were obtained from computer listings. For leavers, date of leaving and reason for leaving were also given. Alphabetical card index systems in the pension department were used to try and identify which of the retirees were still receiving a pension and which had died. For those who had died in service or after retirement and for men who had resigned, full name and last known address were obtained from an alphabetical card index in the personnel department. No National Insurance or National Health Service numbers were available.

As it was thought that the information obtained from the pension department might be incomplete all leavers, except those who died in service, were traced. Tracing was first carried out through the social security records at Newcastle. If this was unsuccessful a request for tracing was then made to the National Health Service Central Register (NHSCR) at Southport. For all men found to be dead full details of death were obtained either directly from the NHSCR or from the Office of Population Censuses and Surveys.

At all stages of the data preparation checks were carried out on the accuracy and plausibility of the data and to eliminate duplicate records.

The computer output for leavers between 1968 and 1975 also included men who had some form of change of job status, including promotion and demotion, changing location within department, transferring to a different grade or department, and changing duties for medical reasons - that is, men who were not really "leavers." Nevertheless, many of them left London Transport subsequently. This resulted in duplicate entries being found for many individuals (about a quarter of all records on the computer output for leavers).

It was assumed that most of the men would live in the same area or close to their location of work. Their area of residence was therefore coded to that of the location of work using the OPCS area code. ${ }^{15}$ London Transport had used over 100 different job titles in the study data and these were coded to 20 broader job groups (table 1). Supervisors and inspectors were combined for analysis, and there were also insufficient numbers of deaths for separate analyses for smiths, trimmers, carpenters, sheet metal workers, and workers in the experimental workshop. Reason for leaving was coded to died in service, retired, or other. The underlying cause of death was coded using the eighth revision of the International Classification of Diseases. ${ }^{16}$

The number of years each man was in the study

Table 1 Distribution of London Transport population by job category (not including untraced men)

\begin{tabular}{lrr}
\hline Job category & No & $(\%)$ \\
\hline Supervisor and foreman & 21 & $(0 \cdot 2)$ \\
Inspector & 202 & $2 \cdot 4$ \\
Smith & 39 & $(0 \cdot 5)$ \\
Electrician and electrical fitter & 373 & $(4 \cdot 4)$ \\
Bodymaker & 365 & $(4 \cdot 3)$ \\
Trimmer & 26 & $0 \cdot 3$ \\
Welder & 52 & $(0 \cdot 6)$ \\
Carpenter & 32 & $(0 \cdot 4)$ \\
Painter & 150 & $(1 \cdot 8)$ \\
Fitter & 431 & $(5 \cdot 1)$ \\
Machinist & 98 & $1 \cdot 2)$ \\
Millwright & 115 & $(1 \cdot 4)$ \\
Toolmaker & 63 & $(0 \cdot 7)$ \\
Panel beater and sheet metal worker & 40 & $(0 \cdot 5)$ \\
Worker in experimental workshop & 38 & $(0 \cdot 4)$ \\
Progress hand & 233 & $(2 \cdot 7)$ \\
Bus mechanic & 2313 & $(27 \cdot 2)$ \\
Security man & 39 & $(0 \cdot 5)$ \\
Office worker & 266 & $(3 \cdot 1)$ \\
General hand & 3594 & $(42 \cdot 3)$ \\
Total & 8490 & $(100 \cdot 0)$ \\
\hline
\end{tabular}


(person years) was calculated from his date of birth and dates of entry to and exit from the study using the man years computer language program. ${ }^{17}$ The total years were subdivided into five year age and calendar period groups. As all men in the study had a minimum of one year's service between 1 January 1967 and 31 December 1975 date of entry to the study was (a) 1 January 1968 for men who joined London Transport before 1967 and (b) one year after joining for those who joined after 1 January 1967.

The expected number of deaths was calculated by applying the five year age and calendar period death rates of the comparison population to the person years. The comparison population used was the male population in England and Wales. Most men in London Transport live and work in Greater London but age and calendar period death rates by detailed cause were not readily available for this area. It was not thought appropriate to adjust the expected numbers of death using published standardised mortality ratios for Greater London as the numbers concerned were small. Differences in mortality between Greater London and the national population, however, have been taken into account when interpreting the results.

The grouping of the causes of death was determined by that of the available comparison data. For 30 malignant causes the groups were those used in the serial mortality tables. ${ }^{18}$ For the non-malignant causes, data for the A list of 150 causes of death from the International Classification of Diseases were made available by the World Health Organisation.

\section{Comparison of observed and expected deaths}

The difference between the observed and expected deaths was examined by calculating a significance level ( $p$ value) for the observed numbers of deaths assuming it to be drawn from a Poisson distribution with mean equal to the externally calculated expected value.

Table 2 Status of study population at study end date, 31 December 1975

\begin{tabular}{lrl}
\hline & No & $(\%)$ \\
\hline In employment & 4671 & $(53 \cdot 8)$ \\
Left employment: & 3102 & $(35 \cdot 7)$ \\
Alive & 701 & $(8 \cdot 1)$ \\
Dead, cause known & 4 & $(0.0)$ \\
Dead, cause unknown & 12 & $\left(\begin{array}{l}0.1 \\
\text { Emigrated }\end{array}\right.$ \\
$\quad$ Untraced & 194 & $(99.9)$ \\
Total & 8684 & $(9.9)$ \\
\hline
\end{tabular}

Two approaches to the analysis were used. Firstly, a search for pronounced excesses and deficits in numbers of observed deaths compared with those expected was made together with an examination of the data by location, age, and job. The significance levels obtained in these analyses were used informally as guidelines to indicate the magnitude and direction of the variations in mortality. The second approach included a priori testing of the findings from previous studies discussed in the introduction.

\section{Results}

Table 2 shows the status of the study population at the study end date, 31 December 1975 . Only $2.2 \%$ of men were untraced. These have not been included in the analysis. There was a total of 50008 person years of observation in the study with a mean follow up of 5.9 years.

The total number of deaths was significantly lower than expected on the basis of the national population (table 3), and especially for rolling stock (O= $495, E=607.46, p<0.0001)$. This deficit was also reflected overall in the numerically large nonmalignant disease groups including cerebrovascular disease, ischaemic heart disease, and bronchitis. Deficits were found in many subgroups of the population defined by location, age, and job for several of the non-malignant causes.

The observed deaths from all neoplasms and cancer of the lung were approximately the same as those expected. There was only one excess, in cancer of the liver and gall bladder at Chiswick Works, although this was based on only four deaths $(O=4$, $E=1.13, p<0.05$ ). Some excesses of observed deaths compared with those expected were found in particular job groups (table 4). Many of these are based on under five deaths and should thus be regarded cautiously. The wide confidence intervals shown in table 4 for some of these excesses reflects the uncertainty in the estimate of $\mathrm{O} / \mathrm{E}$ which is based on such small numbers of deaths. ${ }^{19}$

\section{Discussion}

The mortality overall and from the numerically large non-malignant causes of death is much lower than that of the standard population with which it was compared. This is the type of result found in many studies that compare an industrially employed cohort with the national population which includes those in unstable employment or who are chronically ill or disabled.

Previous studies have investigated coronary heart disease in London Transport workers. In the present 
Table 3 Observed and expected deaths, $O / E$, and $p$ values for all causes, all neoplasms and causes with five or more deaths for maintenance workers employed at London Transport bus garages and Chiswick Works from 1 June 1967 to 31 December 1975

\begin{tabular}{|c|c|c|c|c|}
\hline Causes (in ICD order) & Observed deaths & Expected deaths & $O / E$ & $\boldsymbol{p}$ \\
\hline $\begin{array}{l}\text { All causes } \\
\text { All neoplasms } \\
\text { Cancer of stomach } \\
\text { Cancer of large intestine } \\
\text { Cancer of rectum } \\
\text { Cancer of liver and gall bladder } \\
\text { Cancer of pancreas } \\
\text { Cancer of lung and pleura } \\
\text { Cancer of prostate } \\
\text { Cancer of urinary bladder } \\
\text { Cancer of brain and other parts of central nervous system } \\
\text { Leukaemia } \\
\text { Cerebrovascular disease } \\
\text { Chronic rheumatic heart disease } \\
\text { Ischaemic heart disease } \\
\text { Other diseases of heart } \\
\text { Hypertensive disease } \\
\text { Diseases of arteries } \\
\text { Other diseases of circulatory system } \\
\text { Pneumonia } \\
\text { Bronchitis } \\
\text { Peptic ulcer } \\
\text { Chronic and other nephritis } \\
\text { Motor vehicle accidents }\end{array}$ & $\begin{array}{r}705 \\
216 \\
26 \\
10 \\
5 \\
6 \\
9 \\
102 \\
11 \\
12 \\
7 \\
7 \\
78 \\
8 \\
84 \\
244 \\
15 \\
7 \\
15 \\
6 \\
28 \\
50 \\
6 \\
6 \\
8\end{array}$ & $\begin{array}{r}836.56 \\
226.77 \\
25.51 \\
13.19 \\
9.92 \\
4.09 \\
9.75 \\
101 \cdot 31 \\
8.93 \\
8.64 \\
5.77 \\
4.65 \\
74.41 \\
8.74 \\
276.63 \\
20.33 \\
13.06 \\
17.05 \\
7.87 \\
32.01 \\
64.67 \\
7.20 \\
3.81 \\
10.03\end{array}$ & $\begin{array}{l}0.84 \\
0.95 \\
1.02 \\
0.76 \\
0.50 \\
1.47 \\
0.92 \\
1.01 \\
1.23 \\
1.39 \\
1.21 \\
1.51 \\
0.78 \\
0.92 \\
0.88 \\
0.74 \\
0.54 \\
0.88 \\
0.76 \\
0.87 \\
0.77 \\
0.83 \\
1.57 \\
0.80\end{array}$ & $\begin{array}{c}<0.0001 \\
0.46 \\
0.49 \\
0.24 \\
0.07 \\
0.23 \\
0.49 \\
0.94 \\
0.29 \\
0.16 \\
0.36 \\
0.19 \\
0.03 \\
0.49 \\
0.05 \\
0.14 \\
0.05 \\
0.37 \\
0.33 \\
0.27 \\
0.04 \\
0.42 \\
0.19 \\
0.33\end{array}$ \\
\hline
\end{tabular}

study there were significantly fewer deaths observed overall than expected from ischaemic heart disease and especially in rolling stock and bus mechanics.

Mortality from all neoplasms is only slightly less than expected overall. Nevertheless, a deficit was found for deaths under 55 years of age with the observed deaths approximately equalling those expected for deaths at older ages. An excess in welders and a slight excess in progress hands was found at Chiswick Works.

Overall the observed deaths from lung cancer (102) are about the same as those expected (101) on the basis of national rates. As discussed above no adjustment was made for regional or social class variation in mortality. The SMR for lung cancer in Greater London, in which most of the London
Transport men live and work, is 145-that is, the death rates from lung cancer are higher in Greater London than in the whole of England and Wales. ${ }^{20}$ A crude adjustment of the expected deaths calculated using national rates could be made as in the refinery study (adjusted expected deaths $=$ expected deaths based on national rates $\times$ regional SMR 100). This would increase the overall expected number of lung cancer deaths to 117 giving a deficit (non-significant) of observed deaths. An excess was found in general hands in rolling stock and a regional adjustment would also reduce this excess. The mortality for these men would also not be greater than other men within their social class (V). ${ }^{21}$ There was also an excess from lung cancer in welders, although this was based on only three deaths. The

Table 4 Observed deaths $(O)$, expected deaths $(E), O / E, 95 \%$ confidence interval for $O / E$, and $p$ values for excesses found in job groups

\begin{tabular}{|c|c|c|c|c|c|c|c|c|}
\hline$J o b$ & $\begin{array}{l}\text { Rolling stock (RS)/ } \\
\text { Chiswick Works (CW) }\end{array}$ & Disease group & $O$ & $E$ & $O / E$ & $\begin{array}{l}95 \% \\
\text { inter }\end{array}$ & $\begin{array}{l}\text { lence } \\
O / E\end{array}$ & $p$ \\
\hline $\begin{array}{l}\text { Inspector } \\
\text { Welder } \\
\text { Welder } \\
\text { Painter } \\
\text { Painter } \\
\text { Painter } \\
\text { Progress hand } \\
\text { Progress hand } \\
\text { Bus mechanic }\end{array}$ & $\begin{array}{l}\text { CW } \\
\text { CW } \\
\text { CW } \\
\text { RS } \\
\text { RS } \\
\text { RS } \\
\text { CW } \\
\text { CW } \\
\text { RS }\end{array}$ & $\begin{array}{l}\text { Cancer of liver and gall bladder } \\
\text { All neoplasms } \\
\text { Cancer of lung } \\
\text { Cancer of large intestine } \\
\text { Cancer of bladder } \\
\text { Pneumonia } \\
\text { All neoplasms } \\
\text { Cancer of bladder } \\
\text { Cancer of brain and central } \\
\text { nervous system }\end{array}$ & $\begin{array}{r}2 \\
5 \\
3 \\
2 \\
2 \\
3 \\
12 \\
3 \\
4\end{array}$ & $\begin{array}{l}0.12 \\
1.56 \\
0.71 \\
0.34 \\
0.23 \\
0.86 \\
7.41 \\
0.27 \\
1.25\end{array}$ & $\begin{array}{r}16 \cdot 67 \\
3 \cdot 21 \\
4 \cdot 23 \\
5 \cdot 88 \\
8 \cdot 70 \\
3 \cdot 49 \\
1 \cdot 62 \\
11 \cdot 11 \\
3 \cdot 20\end{array}$ & $\begin{array}{l}2.96 \\
1.26 \\
1 \cdot 15 \\
1.04 \\
1.54 \\
0.95 \\
0.93 \\
3.03 \\
1.10\end{array}$ & $\begin{array}{r}52 \cdot 59 \\
6 \cdot 74 \\
10 \cdot 93 \\
18 \cdot 55 \\
27 \cdot 44 \\
9 \cdot 02 \\
2 \cdot 63 \\
28 \cdot 71 \\
7 \cdot 32\end{array}$ & $\begin{array}{r}<0.01 \\
0.02 \\
0.04 \\
0.05 \\
0.02 \\
0.06 \\
0.07 \\
<0.01 \\
0.04\end{array}$ \\
\hline $\begin{array}{l}\text { Office worker } \\
\text { Office worker } \\
\text { General hand } \\
\text { General hand }\end{array}$ & $\begin{array}{l}\text { CW } \\
\text { CW } \\
\text { CW } \\
\text { RS }\end{array}$ & $\begin{array}{l}\text { All causes } \\
\text { Pneumonia } \\
\text { Cancer of pancreas } \\
\text { Cancer of lung }\end{array}$ & $\begin{array}{r}16 \\
2 \\
3 \\
48\end{array}$ & $\begin{array}{r}10.24 \\
0.36 \\
0.83 \\
36 \cdot 11\end{array}$ & $\begin{array}{l}1.56 \\
5.56 \\
3.61 \\
1.33\end{array}$ & $\begin{array}{l}0.98 \\
0.99 \\
0.98 \\
1.03\end{array}$ & $\begin{array}{r}2 \cdot 37 \\
17 \cdot 54 \\
9 \cdot 33 \\
1.69\end{array}$ & $\begin{array}{l}0.06 \\
0.05 \\
0.05 \\
0.03\end{array}$ \\
\hline
\end{tabular}


above comments on regional variation in mortality apply to this excess. Other work has suggested an association between welding fumes and impairec lung function, ${ }^{22}$ and lung cancer. ${ }^{23} \mathrm{~A}$ major problem in the intepretation of results for lung cancer is the lack of information on smoking habits. It is understood that at the end of the war about $15 \%$ of the bus fleet were still using petrol but these had all been replaced by diesel engines by 1950 . Restriction on smoking was then lifted from 1950 onwards in all garages (PAB Raffle, personal communication).

Several other excesses were found for various sites of malignant disease in subgroups of the population. Some of these, such as the excess from lung cancer in welders referred to above, have also been suggested in previous work - for example, cancer of the bladder in painters. ${ }^{21}$ As discussed earlier, however, they are all based on very small numbers of deaths, and the uncertainty in the estimate of the ratio of observed over expected deaths is reflected in the wide confidence intervals obtained for some of the results in table 4 . Previous studies have shown an association between exposure to mineral oil and skin cancer. There was only one death from this disease, fewer than expected.

The national age and calendar period mortality rates used for comparison reflect to some extent the changes in social habits and lifestyle over the eight years of the study. There is no evidence to suggest that these changes differ between the study and the comparison populations.

The cause of death information obtained from the death details may be subject to inaccuracy through omission of information, misdiagnosis, or errors of classification and coding. ${ }^{24} 25$ The difficulty of interpreting results from this type of study, where many comparisons of observed and expected deaths are made, is increased when, as in the present study, the numbers are small and the period of follow up is short.

Altogether 71 bus garages were included, with the number of men eligible over the study period from the individual garages varying from six to 99 . The numbers of men and numbers of deaths from each garage were thus rather small for formal analysis. Nevertheless, there was no indication from an informal examination of the deaths by bus garage that any individual garage was particularly concerned.

\section{Conclusions}

This study of London Transport maintenance workers has not highlighted any problem areas which might indicate that further investigation was needed. The information was limited, however, in both the numbers of men in the study and the detail collected on each man. The duration of follow up was also, short, an average of only six years. The numbers of deaths by different causes were small, making it difficult to exclude chance effects. An extension of the duration of follow up and inclusion of leavers from additional years would increase the numbers of deaths, especially in causes with a long latent period, and might help to indicate whether any areas need further investigation.

About half of the leavers in this study were men who left for reasons other than death or retirement and had to be traced through the national systems (a fairly lengthy procedure) to establish their vital status. Nevertheless, they contributed only $43(6 \%)$ of the deaths. A useful study might thus be carried out more quickly using only records of men in service, retirees, and deaths in service and not tracing men leaving for other reasons if information was thought to be sufficiently accurate and complete.

The data for this study were handled by Mrs Carol Fair and Ms Deborah Cummings. We benefited by help from many colleagues especially $\mathrm{Dr}$ Joan Davies and Mrs Doreen Folkes.

The basic information was obtained from records in the London Transport administrative and pension departments and thanks go to all those personnel concerned. We are grateful to OPCS, DHSS, and the Registrar General for Scotland for tracing the leavers. The study benefited from the guidance of a working party of the Institute of Petroleum, in particular from Dr W L B Leese and Dr P A B Raffle. The main funding of the project was a grant from the Institute of Petroleum. The Cancer Research Campaign support of the division of epidemiology is also gratefully acknowledged.

Requests for reprints to: Dr L Rushton, Thames Polytechnic, School of Mathematics, Statistics and Computing, Wellington Street, London SE18 6PF.

\section{References}

${ }^{1}$ Rushton L, Alderson MR. An epidemiological survey of eight oil refineries in Britain. $B r J$ Ind Med 1981;38:225-34.

2 Rushton L, Alderson MR. An epidemiological survey of oil distribution centres in Great Britain. Final report. London: Institute of Petroleum, 1982.

${ }^{3}$ Rushton L, Alderson MR. A case-control study to investigate the association between exposure to benzene and deaths from leukaemia in oil refinery workers. $\mathrm{Br} J$ Cancer 1981;43:77-84.

4 Morris JN, Heady JA, Raffle PAB. Coronary heart disease and physical activity of work. Lancet 1953;i:1053-7, 1111-20.

${ }^{5}$ Morris JN, Raffle PAB. Coronary heart disease in transport workers. A progress report. Br J Ind Med 1954;11:260-4.

- Morris JN, Heady JA. Raffle PAB. Physique of London busmen. Epidemiology of uniforms. Lancet 1956;i:569-70.

${ }^{7}$ Morris JN, Kagan A, Pattison DC, Gardner MJ, Raffle PAB. 
Incidence and prediction of ischaemic heart disease in London busmen. Lancet 1966; i:553-9.

${ }^{8}$ Heady JA, Morris JN, Lloyd FJ, Raffle PAB. Sickness absence before the first clinical episode of coronary heart disease. $\mathrm{Br} J$ Ind Med 1954;11:20-4.

${ }^{9}$ Heady JA, Morris JN, Kagan A, Raffle PAB. Coronary heart disease in London busmen. A progress report with particular reference to physique. Br J Prev Soc Med 1961;15:143-53.

${ }^{10}$ Raffle PAB. The health of the worker. Br J Ind Med 1957;14:73-80.

"Raffle PAB. Stress as a factor in disease. Lancet 1959;i:839-43.

12 Commins BT, Waller RE, Lawther PJ. Air pollution in diesel bus garages. Br J Ind Med 1957;14:232-9.

${ }^{13}$ Schenker MB. Diesel exhaust-an occupational carcinogen? JOM 1980;22:41-6.

14 Waller RE. Trends in lung cancer in London in relation to exposure to diesel fumes. Environmental International 1981;5:479-83.

is Office of Population Censuses and Surveys. Area code for recording place of residence and place of birth. London: OPCS, 1974.

${ }^{16}$ World Health Organisation. Manual of the international classification of diseases, injuries and causes of deaths. Vols 1 , 2. Geneva: WHO, 1967.
${ }^{17}$ Hill ID. Computing man years at risk. Br J Prev Soc Med 1973;26:132-4.

${ }^{18}$ Case RAM, Coghill C, Davies JM, et al. Serial mortality tables, neoplastic diseases. Vol 1. England and Wales 1911-70. London: Institute of Cancer Research, 1976.

19 Bailar JC, Ederer F. Significance factors for the ratio of a Poisson variable to its expectation. Biometrics 1964;20:639-43.

${ }^{20}$ Office of Population Censuses and Surveys. Mortality statistics area 1975. London: HMSO, 1977. (Series DH5 No 2.)

${ }^{21}$ Office of Population Censuses and Surveys. Occupational mortality 1970-72. London: HMSO, 1978. (Series DS No 1.)

${ }^{22}$ Arbarkhanzadeh $F$. Long-term effects of welding fumes upon respiratory symptoms and pulmonary function. JOM 1980;22:337-41.

${ }^{23}$ Beaumont JJ, Weiss NS. Lung cancer among welders. JOM 1981;23:839-44.

${ }^{24}$ Alderson MR. The accuracy of the certification of death and the classification of the underlying cause of death from the death certificate. London: London University, 1965. (MD thesis.)

${ }^{25}$ Waldron HA, Vickerstaff L. Intimations of quality: ante-mortem and post-mortem diagnosis. London: Nuffield Provincial Hospitals Trust, 1977. 